\title{
GENETIC ANALYSIS UTILIZING SINGLE GERMSPORANGIA IN TWO SPECIES OF RHIZOPUS
}

\author{
WENDELL GAUGER \\ School of Biological Sciences, University of \\ Nebraska, Lincoln, NE 68588-0118, USA
}

(Received July 24, 1984)

\begin{abstract}
Three-factor crosses in both Rhizopus stolonifer and $R$. microsporus gave results which supported the hypothesis that normal sexual functions (karyogamy and meiosis) were operating in these species. However, not all meiotic products are recovered in the germsporangium of each germinating zygospore. When the number of germsporangia containing each genotype were scored, the sizes of the eight possible genotypes obtainable from a three-factor cross were found to be approximately equal. Likewise, allelic recovery values were approximately equal. Parental/recombinant figures indicate that none of the loci studied ( 3 in $R$. stolonifer and 4 in $R$. microsporus) were linked. Classification of each germsporangium according to the number and kinds of genotypes recovered revealed that $35 \%$ of those in $R$. stolonifer and $17 \%$ of those in $R$. microsporus contained products of more than one meiosis.
\end{abstract}

This study is part of a continuing series attempting to elucidate the transmission genetics of the mucoraceous fungi. Although the phenomenon of heterothallism in fungi was first described by BLAKESLEE (1) in this group of fungi, subsequent genetic studies have not been extensive. One of the reasons for this lack of interest has been the difficulty encountered in germinating the zygospores. The interest of the late Max Delbrück and his co-workers in the sensory phenomena exhibited by the sporangiophore of Phycomyces blakesleeanus Burgeff has resulted in significant advances in understanding the genetics of that organism (2-6).

Life cycle. This account is based on results of studies with $P$. blakesleeanus, but is consistent with results from Rhizopus stolonifer Ehrenb. ex Fr. (Vuill.) (7). Following fusion of multinucleate gametangia produced by compatible mating strains, a thick-walled zygospore is formed. After a dormancy period of 2 months or more, the zygospore germinates to form a germsporangium containing, in $P$. blakesleeanus, 10,000 or more germspores. Nuclear fusion and meiosis occur at 
unknown times in the zygospore. The nuclei contained within the germspores are mitotic descendants of nuclei which resulted from meiosis.

It is usually the case that only nuclei descending from the products of a single meiosis are recovered in the germspores. However, nuclei representing more than one meiosis are occasionally found. It is also usually the case that germspores are homokaryotic.

Recovery of alleles from a group of germsporangia gives a close fit to an expected 1:1 ratio implying an absence of agamic nuclei. For pairs of loci, parental: recombinant ratios may give evidence of linkage (5).

Classification of germsporangia. Among the sampled representatives of a single germsporangium one may find, from a two-factor cross, one, two, three or four genotypes. From three- or four-factor crosses more genotypes may be found. Two kinds of germsporangia containing a single genotype are recognized: 1TP (parental) or 1TR (recombinant). Among germsporangia with two genotypes we recognize two types also: $2 \mathrm{~T}_{\text {rec }}$ (reciprocal) and $2 \mathrm{~T}_{\text {mixed }}$ (non-reciprocal). $3 \mathrm{~T}$ germsporangia are either $3 \mathrm{~T}$ or $3 \mathrm{~T}_{\mathrm{pse}}$. $3 \mathrm{~T}_{\mathrm{pse}}$ germsporangia contain at least one allele represented more than twice. $4 \mathrm{~T}$ germsporangia can be either $4 \mathrm{~T}$ (reciprocal pairs only) or $4 \mathrm{~T}_{\mathrm{pse}}$ (at least one allele represented more than twice). The final type is $>4 \mathrm{~T} . \quad 3 \mathrm{~T}_{\mathrm{pse}}, 4 \mathrm{~T}_{\mathrm{pse}}$ and $>4 \mathrm{~T}$ germsporangia originate from nuclei derived from more than one meiosis. This classification scheme was first described by EsLAva et al. (2).

Among the sources of error encountered in analyzing single germsporangia are: 1) sampling error, 2) preferential loss of certain meiotic nuclei and 3) differential abilities of meiotic nuclei to divide mitotically.

Data provided by single germsporangium analysis. After sampling the germspores in a number of germsporangia we obtain a total for each genotype identified. A second value, termed the "presence or absence" (P/A) value (3) can also be determined. This value is the total number of germsporangia containing at least one representative of each genotype. Use of the P/A figure was considered to ". . . minimize the effects of secondary mechanisms, such as asynchrony in the post meiotic divisions of the haploid products." (3).

Workers with $P$. blakesleeanus have generally preferred to sample the pooled contents of several germsporangia rather than individual germsporangia (5).

Studies with $R$. stolonifer (two-factor crosses) using single germsporangia revealed that closer fits to expected values was obtained from P/A values than from total germspore isolate figures (7).

A third species, Mucor hiemalis Wehmer, has also been analyzed genetically (8). Germsporangia contained, in most cases, only one genotype. Allele recovery ratios differed markedly from the expected 1:1 and the sizes of reciprocal genotypic classes were often unequal. The reason(s) for these distortions are not known. 


\section{MATERIALS AND METHODS}

Strains used. A list of strains used as parents, as well as the crosses they were used in, are shown in Table 1.

Media. Parental strains of $R$. stolonifer were coinoculated on Malt Extract Agar consisting of $2 \%$ Difco Malt Extract (w/v) and 1.5\% Difco Agar (w/v). $R$. microsporus van Tiegh. crosses were made on Yeast Extract Agar (YEA) which contained D-glucose, $0.4 \%(\mathrm{w} / \mathrm{v})$; Difco Yeast Extract, $0.4 \%(\mathrm{w} / \mathrm{v})$; Difco Malt Extract, $1 \%(\mathrm{w} / \mathrm{v})$ and Difco Agar, $1.5 \%(\mathrm{w} / \mathrm{v})$. Minimal medium for both species was a glucose asparagine medium known as SM (7).

Table 1. Strains used in this study and crosses made.

\begin{tabular}{|c|c|}
\hline Rhizopus stolonifer & Cross \\
\hline UNB $152(+)$ wild type & $\mathrm{C}$ \\
\hline UNB $153(-)$ wild type & $\mathrm{D}$ \\
\hline UNB $282(+)$ ade & A \\
\hline UNB 283 (-) sul & A \\
\hline UNB $286(+)$ sul & $\mathbf{B}$ \\
\hline UNB $287(-)$ ade & B \\
\hline UNB $288(-)$ ade sul & $\mathrm{C}$ \\
\hline UNB $290(+)$ ade sul & $\mathrm{D}$ \\
\hline \multicolumn{2}{|l|}{ Rhizopus microsporus } \\
\hline CBS $699.68(+)$ wild type & G \\
\hline CBS $700.68(-)$ wild type & $\mathbf{H}$ \\
\hline UNB $320(+)$ ade & $\mathrm{E}$ \\
\hline UNB $318(-)$ arg & $\mathrm{E}$ \\
\hline UNB $300(+)$ arg & $\mathrm{F}$ \\
\hline UNB $319(-)$ ade & $\mathrm{F}$ \\
\hline UNB 307 (-) ade arg & G \\
\hline UNB $308(+) \arg$ & $\mathrm{K}$ \\
\hline UNB $304(-)$ sul & $\mathrm{J}, \mathrm{K}$ \\
\hline UNB $303(+)$ ade & $\mathbf{J}$ \\
\hline UNB $306(+)$ ade arg & $\mathbf{H}$ \\
\hline
\end{tabular}

$\mathrm{CBS}=$ Centraalbureau voor Schimmelcultures, Baarn, The Netherlands.

$\mathrm{UNB}=$ Culture collection, University of Nebraska School of Biological Sciences, Lincoln, NE.

$R$. stolonifer was grown at room temperature $\left(25^{\circ}\right)$ while $R$. microsporus was grown at $30^{\circ}$.

Isolation and germination of zygospores. The isolation and holding of zygospores of $R$. stolonifer for germination have been described (7). A modification of the isolation procedure was developed for $R$. microsporus. Following the initial centrifugation of the zygospores they were suspended in a concentrated solution of sucrose $(62 \%)$. The sucrose was overlayed with about $1 \mathrm{ml}$ of water. The suspension was then centrifuged at about 3,000 rpm for $15 \mathrm{~min}$. Zygospores became concentrated at the interface while vegetative spores and mycelial debris 
formed an indistinct pellet. The zygospores were removed with a Pasteur pipette and rinsed with water 3 or 4 times. They were then incubated overnight in a dilute, liquid medium (glucose, $0.02 \%$; peptone, $0.01 \%$, both w/v). This step promoted growth of residual vegetative contamination which was removed the following morning with an inoculating needle. The sucrose centrifugation step was repeated and the zygospores again rinsed. The zygospores were then placed on water agar plugs which, in turn, were held in vials supported by filter paper and filter discs (7). The method resulted in zygospores almost completely free of vegetative contamination. Contaminated vials were discarded. Vials containing zygospores were held at $25^{\circ}$.

The germsporangia of germinating zygospores were removed with fine forceps and transferred to Petri dishes containing either MEA or YEA. The germspores were spread over the surface of the agar with a sterile spreader. Since the germsporangia of $R$. microsporus were considerably smaller than those of $R$. stolonifer, extra care was necessary to remove them from the vials. The entire plug was taken from the vial and placed in an empty sterile Petri dish. This allowed easier manipulation in removing the germsporangia.

Germspores were allowed $10-12 \mathrm{hr}$ to germinate at which time they were removed and transferred singly to MEA or YEA slants. Ten germspores were isolated from each germsporangium.

Determination of genotype. Spores of single germspore isolates were transferred to liquid minimal medium. If no growth occurred in $20-24 \mathrm{hr}$, individual growth factors were added and the tube reincubated. If no growth appeared after this second incubation a second growth factor was added to the tube and at the same time a second tube of minima! medium was inoculated and the second growth factor added singly to it.

Mating-type was determined by inoculating the isolate against $(+)$ and (-) tester strains. The mating reaction was usually not visible in $R$. stolonifer except under the dissecting microscope. The mating reaction in $R$. microsporus resulted in a very obvious yellow zone where the compatible strains met.

Mutant production and characterization. The ade mutant of $R$. stolonifer was induced using nitrous acid following the technique of SIDDIQI (9). All other mutants were obtained following treatment of the spores with $\mathrm{N}$-methyl- $\mathrm{N}^{\prime}$-nitro$\mathrm{N}$-nitrosoguanidine using the method of Heisenberg and Cerdí-Olmedo (10).

Mutant selection was made easier in $R$. microsporus by using a technique known as "recycle/filter enrichment." Following mutagenesis the spores were plated on a complete medium (MEA or YEA) and allowed to grow to sporulation. These "recycled" spores were then harvested, concentrated by centrifugation and incubated overnight in liquid minimal medium on a rotary shaker. The resulting mycelial growth was then removed by filtration and the remaining ungerminated spores carried through another round of filtration enrichment. The remaining ungerminated spores were then plated on MEA or YEA containing $0.24 \mathrm{~g} / l(\mathrm{w} / \mathrm{v})$ 
of Triton X100 to induce colonial growth.

Colonies appearing on complete medium were transferred to MEA or YEA slants and allowed to sporulate. Isolates failing to grow on minimal medium were then tested for specific growth-factor requirement. Since the recycling step allowed for mitotic increase of induced auxotrophs, care was taken not to save more than one auxotroph of each kind from any recycled plate. The recycling portion of this technique has been used by workers with P. blakesleeanus for some time. A recent publication examines the method in more detail (11). The filtration enrichment procedure is a standard method of enriching for auxotrophs in filamentous fungi.

The ade strain of $R$. microsporus showed a reddish coloration reminiscent of ade 3 mutants of Neurospora crassa Shear \& B. O. Dodge. The arg mutant of $R$.

Table 2. Genotypes obtained from three-factor crosses in Rhizopus stolonifer (crosses A, B, C, D) and $R$. microsporus (crosses E, F, G, H, J, K).

\begin{tabular}{|c|c|c|c|c|c|c|c|c|c|c|c|}
\hline Cross & mat $\begin{array}{c}(+) \\
\text { ADE } \\
\text { SUL }\end{array}$ & $\begin{array}{c}(+) \\
\text { ADE } \\
\text { sul }\end{array}$ & $\begin{array}{l}(+) \\
\text { ade } \\
\text { SUL }\end{array}$ & $\begin{array}{l}(+) \\
\text { ade } \\
\text { sul }\end{array}$ & $\begin{array}{l}(-) \\
\text { ADE } \\
\text { SUL }\end{array}$ & $\begin{array}{c}(-) \\
\text { ADE } \\
\text { sul }\end{array}$ & $\begin{array}{l}(--) \\
\text { ade } \\
\text { SUL }\end{array}$ & $\begin{array}{l}(-) \\
\text { ade } \\
\text { sul }\end{array}$ & $\begin{array}{l}\text { No. } \\
\text { GSp }\end{array}$ & $\begin{array}{c}\text { Avg. No. } \\
\text { genotypes } \\
\text { per GSp }\end{array}$ & $\begin{array}{l}\text { Shortest } \\
\text { dormancy } \\
\text { (days) }\end{array}$ \\
\hline A & 14 & 21 & 11 & 19 & 11 & 18 & 10 & 17 & 47 & 2.6 & 88 \\
\hline B & 13 & 13 & 10 & 12 & 13 & 15 & 9 & 16 & 47 & 2.2 & 92 \\
\hline $\mathrm{C}$ & 17 & 14 & 13 & 18 & 22 & 20 & 20 & 20 & 48 & 3.1 & 68 \\
\hline \multirow[t]{2}{*}{ D } & 8 & 18 & 16 & 20 & 11 & 13 & 11 & 17 & 49 & 2.3 & 71 \\
\hline & $\begin{array}{r}\text { mat }(+) \\
\text { ADE } \\
\text { ARG }\end{array}$ & $\begin{array}{c}(+) \\
\text { ADE } \\
\text { arg }\end{array}$ & $\begin{array}{l}(+) \\
\text { ade } \\
\text { ARG }\end{array}$ & $\begin{array}{l}(+) \\
\text { ade } \\
\text { arg }\end{array}$ & $\begin{array}{l}(-) \\
A D E \\
A R G\end{array}$ & $\begin{array}{c}(-) \\
\text { arg }\end{array}$ & $\begin{array}{c}(-) \\
\text { ade } \\
\text { ARG }\end{array}$ & $\begin{array}{l}(-) \\
\text { ade } \\
\text { arg }\end{array}$ & & & \\
\hline$E$ & 9 & 15 & 19 & 15 & 11 & 16 & 10 & 9 & 41 & 2.5 & 32 \\
\hline $\mathrm{F}$ & 11 & 7 & 14 & 10 & 5 & 10 & 15 & 10 & 36 & 2.3 & 37 \\
\hline $\mathrm{G}$ & 6 & 4 & 13 & 10 & 15 & 10 & 11 & 9 & 41 & 1.9 & 32 \\
\hline \multirow[t]{2}{*}{$\mathrm{H}$} & 7 & 9 & 10 & 10 & 6 & 7 & 18 & 9 & 42 & 1.8 & 32 \\
\hline & $\begin{array}{c}\text { mat }(+) \\
\text { ADE } \\
\text { SUL }\end{array}$ & $\begin{array}{c}(+) \\
\text { ADE } \\
\text { sul }\end{array}$ & $\begin{array}{c}(+) \\
\text { ade } \\
\text { SUL }\end{array}$ & $\begin{array}{c}(+) \\
\text { ade } \\
\text { sul }\end{array}$ & $\begin{array}{l}(-) \\
\text { ADE } \\
\text { SUL }\end{array}$ & $\begin{array}{c}(-) \\
\text { ADE } \\
\text { sul }\end{array}$ & $\begin{array}{l}(-) \\
\text { ade } \\
\text { SUL }\end{array}$ & $\begin{array}{l}(-) \\
\text { ade } \\
\text { sul }\end{array}$ & & & \\
\hline \multirow[t]{2}{*}{$\mathbf{J}$} & 9 & 15 & 14 & 10 & 14 & 10 & 9 & 9 & 40 & 2.3 & 25 \\
\hline & $\begin{array}{c}\text { mat }(+) \\
\text { ARG } \\
\text { SUL }\end{array}$ & $\begin{array}{c}(+) \\
\text { ARG } \\
\text { sul }\end{array}$ & $\begin{array}{c}(+) \\
\text { arg } \\
\text { SUL }\end{array}$ & $\begin{array}{l}(+) \\
\text { arg } \\
\text { sul }\end{array}$ & $\begin{array}{l}(-) \\
\text { ARG } \\
\text { SUL }\end{array}$ & $\begin{array}{c}(-) \\
\text { ARG } \\
\text { sul }\end{array}$ & $\begin{array}{c}(-) \\
\text { arg } \\
\text { SUL }\end{array}$ & $\begin{array}{l}(-) \\
\text { arg } \\
\text { sul }\end{array}$ & & & \\
\hline $\mathrm{K}$ & 12 & 9 & 16 & 13 & 11 & 12 & 9 & 15 & 37 & 2.6 & 43 \\
\hline
\end{tabular}

mat $=$ mating-type.

ADE: ade=adenine prototroph and auxotroph, respectively.

SUL: sul=sulfur (methionine, cysteine) prototroph and auxotroph, respectively.

ARG : $\arg =$ arginine prototroph and auxotroph, respectively.

$\mathrm{GSp}=$ germsporangia.

See Table 1 for parents of various crosses.

Shortest dormancy=days from inoculation of parents until first zygospore germination.

Figures represent the number of germsporangia containing each allelic combination. 
microsporus grew on ornithine, citrulline and proline in addition to arginine, but did not grow on glutamic acid. sul mutants of both species grew on both methionine and cysteine.

Treatment of the data. Only P/A values are given in Tables 2-4. None of the figures in these tables includes germspore isolates which were mating-type heterokaryons. Nor was any attempt made to calculate zygospore germination percentages. Large numbers of zygospores were isolated and examined for each cross, usually between 2,000 and 4,000. Time did not permit examination of these zygospores until we could be assured that all of the viable zygospores had germinated. The collection of germsporangia usually extended over a period of four to eight weeks.

Table 3. Allele recovery for three-factor crosses in Rhizopus stolonifer (crosses A, B, C, D) and $R$. microsporus (crosses E, F, G, H, J, K).

\begin{tabular}{ccccc}
\hline Cross & $(+):(-)$ & ADE $:$ ade & SUL $:$ sul & ARG $:$ arg \\
\hline A & $65: 56$ & $64: 57$ & $46: 75$ & \\
B & $48: 53$ & $54: 47$ & $45: 56$ & \\
C & $62: 82$ & $73: 71$ & $72: 72$ & \\
D & $62: 52$ & $50: 64$ & $46: 68$ & \\
E & $58: 46$ & $51: 53$ & & $49: 55$ \\
F & $42: 40$ & $33: 49$ & & $45: 37$ \\
G & $33: 45$ & $35: 43$ & & $45: 33$ \\
H & $36: 40$ & $29: 47$ & & $41: 35$ \\
J & $48: 42$ & $48: 42$ & $46: 44$ & \\
K & $50: 47$ & & $48: 49$ & $44: 53$ \\
\hline
\end{tabular}

See Legend for Table 2.

Table 4. Parental/recombinant ratios for three-factor crosses in Rhizopus stolonifer (crosses A, B, C, D) and R. microsporus (crosses E, F, G, H, J, K).

\begin{tabular}{lcccccc}
\hline Cross & $\begin{array}{c}\text { mat-ade } \\
(\mathrm{P}: \mathrm{R})\end{array}$ & $\begin{array}{c}\text { mat-sul } \\
(\mathrm{P}: \mathrm{R})\end{array}$ & $\begin{array}{c}\text { mat-arg } \\
(\mathrm{P}: \mathrm{R})\end{array}$ & $\begin{array}{c}\text { ade-arg } \\
(\mathrm{P}: \mathrm{R})\end{array}$ & $\begin{array}{c}\text { ade-sul } \\
(\mathrm{P}: \mathrm{R})\end{array}$ & $\begin{array}{c}\text { arg-sul } \\
(\mathrm{P}: \mathrm{R})\end{array}$ \\
\hline A & $59: 62$ & $60: 61$ & & & $60: 61$ & \\
B & $51: 50$ & $47: 54$ & & & $47: 54$ & \\
C & $71: 73$ & $70: 74$ & & & $77: 67$ & \\
$\mathrm{D}$ & $60: 54$ & $60: 54$ & & & $56: 58$ & \\
E & $61: 43$ & & $53: 51$ & $60: 44$ & & \\
F & $43: 39$ & & $37: 45$ & $46: 36$ & & \\
G & $30: 48$ & & $38: 40$ & $40: 38$ & & \\
H & $43: 33$ & & $33: 43$ & $32: 44$ & & \\
J & $48: 42$ & $42: 48$ & & & $48: 42$ & \\
K & & $42: 55$ & $52: 45$ & & & $46: 51$ \\
\hline
\end{tabular}

See Legend for Table 2. 


\section{RESULTS}

The morphology of zygospore germination in the two species was quite different. The larger zygospores (120-150 $\mu \mathrm{m}$ dia.) of $R$. stolonifer most commonly germinated by producing a germsporangiophore directly. Less frequently, a stolon was formed which, in turn, terminated in a germsporangiophore and germsporangium. In the less robust $R$. microsporus zygospores (50-75 $\mu \mathrm{m}$ dia.) typically gave rise to three or four stolons, each of which terminated in a germsporangiophore and germsporangium. Rarely, the stolon scontinued to grow and no discernable germsporangia were produced.

Germsporangia of $R$. stolonifer contained an average of approximately 400 germspores. In $R$. microsporus the average number of germspores from all germsporangia produced by one zygospore was about 300 .

In $R$. stolonifer, all four possible reciprocal three-factor crosses involving three markers were studied. In $R$. microsporus, six three-factor crosses involving four markers were examined. The results from these crosses are shown in Table 2.

When the results were compared to a null hypothesis (non-linkage of all three markers) using a chi square test, in no case was the variation significant at the $5 \%$ level.

The data in Table 2 is rearranged in Tables 3 and 4 to show allele recovery and parental/recombinant ratios respectively. Significant variation in allele recovery was found in two instances; in cross A with the $S U L$ : sul markers and in cross $\mathrm{H}$ with the $A D E$ : ade markers. In Table 4 there is only one case of significant variation at the $5 \%$ level (Cross G, mat: ade loci). In all other cases, the data support the hypothesis of non-linkage of all markers.

Table 5 contains a summary of the distribution of germsporangia according to the kinds and arrangement of the germspore isolates taken from individual sporangia. Thirty-five percent of the germsporangia in $R$. stolonifer and $17 \%$ of those

Table 5. Distribution of germsporangia in three-factor crosses of Rhizopus stolonifer and $R$. microsporus.

\begin{tabular}{ccc}
\hline GSp type & R. stolonifer (4 crosses) & R. microsporus (6 crosses) \\
\hline $1 \mathrm{TP}$ & 15 & 15 \\
$1 \mathrm{TR}$ & 33 & 51 \\
$2 \mathrm{~T}_{\mathrm{rec}}$ & 0 & 21 \\
$2 \mathrm{~T}_{\mathrm{mix}}$ & 58 & 66 \\
$3 \mathrm{~T}$ & 15 & 40 \\
$3 \mathrm{~T}_{\mathrm{pse}}$ & 29 & 13 \\
$4 \mathrm{~T}$ & 0 & 5 \\
$4 \mathrm{~T}_{\mathrm{pse}}$ & 23 & 24 \\
$>4 \mathrm{~T}$ & 14 & 2 \\
\hline & Totals & 237
\end{tabular}

$\mathrm{GSp}=$ germsporangium.

See text for descriptions of GSp type. 
in $R$. microsporus contained products from more than one meiosis. The comparable value for $P$. blakesleeanus was $9 \%$ (3).

Most germspore isolates appeared to be homokaryotic. An estimate of the frequency of heterokaryosis among single germspore isolates was obtained by observing the presence of zygospores in such isolates. In $R$. microsporus, matingtype heterokaryons produced a distinctive yellow color, typical of the sexual reaction zone between opposite mating types. In addition, the culture produced azygospores which accounted, in part, for the yellow coloration. In $R$. stolonifer the presence of zygospores and the sexual reaction with both $(+)$ and $(-)$ tester strains were the only hints of a mating-type heterokaryon. The presence of zygospores had to be determined under the dissecting microscope.

In $R$. microsporus, 98 out of $2,332(4.2 \%)$ germspore isolates were matingtype heterokaryons. Mating-type heterokaryons were found in 49 out of 239 $(20.5 \%)$ germsporangia collected from the six crosses. Comparable values for $R$. stolonifer are $0.8 \%$ (14 out of a total of 1,741 germspore isolates) and 5.2\% (10 germsporangia out of a total of 191). The lower values for $R$. stolonifer was likely due, in part, to the increased difficulty of identifying mating-type heterokaryons in that species.

\section{DISCUSSION}

The results obtained from crosses in $R$. stolonifer and $R$. microsporus are in general agreement with those obtained with $P$. blakesleeanus. They support the hypothesis that classical meiosis and recombination systems are operative in these two species. The data obtained from single germsporangial analysis differ markedly from those fungi which are strict tetrad fungi, such as Neurospora crassa, Saccharomyces cerevisiae Hansen and Schizophyllum commune Fr. ex Fr. Not all meiotic products are recovered in a single germsporangium every time. Rather, various combinations of genotypes from one, or in some cases more, meiosis are found among the sampled germspores from a single germsporangium. It is significant that with increased parental isogenicity, the frequency of 2TR and 4T germsporangia increases in P. blakesleeanus (6). While the two-factor crosses used in those studies will not provide evidence for the presence of products of more than one meiosis, it seems clear that meiotic regularity is more frequent in isogenic crosses.

In spite of these complicating factors, a summary of the presence or absence of each genotype in the germsporangia revealed that allele recovery at each locus studied was close to an expected 1:1 ratio (with two exceptions noted in the Results). The appearance of genotype classes from the crosses studied were also in close agreement with expectations (with one exception noted in the RESULTS) as were parental recombinant class sizes, assuming non linkage.

There would appear to be little reason to use single germsporangial analysis as 
opposed to the method commonly used by Phycomyces workers; namely the pooling of the germsporangia from several zygospore germinations and sampling the mixture, especially since the data obtained from pooling appears very regular. However, zygospores of $P$. blakesleeanus tend to germinate in a restricted period of time and zygospore viability is usually quite high. In the two species of Rhizopus reported here, zygospore germinations are usually sporadic and occur over a one or two month period. This makes pooling impractical without a considerable scaling up of the number of zygospores examined.

The value of using isogenic parents, however, seems to be uncontestable. The parents used in my crosses were not of the same degree of isogenicity as those reported by Alvarez and Eslava (6). The $R$. stolonifer crosses were between parents representing the third and fourth backcross generations while the $R$. microsporus parents were mostly from the second backcross generation.

I would like to acknowledge the technical assistance of M. Doty, D. Owen and D. Beyer.

\section{REFERENCES}

1) A. F. Blakeslee, Proc. Am. Acad. Arts Sci., 40, 205 (1904).

2) A. P. Eslava, M. I. Alvarez, P. V. Burke and M. Delbrück, Genetics, 80, 445 (1975).

3) A. P. Eslava, M. I. Alvarez and M. Delbrück, Proc. Natl. Acad. Sci. U. S. A., 72, 4076 (1975).

4) E. Cerdá-Olmedo, Genet. Res., 3, 285 (1975).

5) M. I. Alvarez, M. I. Pelaez and A. P. Eslava, Mol. Gen. Genet., 179, 447 (1980).

6) M. I. Alvarez and A. P. Eslava, Genetics, 105, 873 (1983).

7) W. L. Gauger, J. Gen. Microbiol., 101, 211 (1977).

8) F. R. JAmes and W. GAUGer, Mycologia, 74, 744 (1982).

9) O. H. SIDDIQI, Genet. Res., 3, 303 (1962).

10) M. Heisenberg and E. Cerdá-Olmedo, Mol. Gen. Genet., 102, 187 (1968).

11) M. I. Roncero, C. Zabala and E. Cerdá-Olmedo, Mut. Res., 125, 195 (1984). 